\title{
Puesta en escena, notaciones escénicas y comunicación
}

\author{
José Ignacio LoRENTE BILBAO \\ Universidad del País Vasco \\ eneko.lorente@ehu.es
}

\begin{abstract}
Resumen
Las notaciones escénicas constituyen un amplio conjunto de prácticas textuales escasamente indagadas tanto en el campo de la investigación en comunicación, como en el ámbito de las artes escénicas. Sin embargo, las didascalias, los cuadernos de dirección y las notaciones escénicas, constituyen un objeto relevante para la investigación en comunicación y para la investigación artística en general, pues guardan memoria tanto del modo en que se ha construido el enunciado escénico, como de las teorías implícitas y las estrategias que han guiado el proyecto enunciativo.
\end{abstract}

Palabras clave: artes escénicas, notaciones escénicas, puesta en escena, dramaturgia, comunicación

\section{Staging, performing notations and communication}

\begin{abstract}
The performing notations are a wide range of textual practices being sparcely investigated both in the field of communication research, as in the field of performing arts. However, the staging directions, directing notebooks and notations in performing arts, are an important subject for research in communication and for the artistic research in general, as they keep memory of how the staging text has been constructed, as implicit theories and strategies that have guided the staging project.
\end{abstract}

Key words: performing arts, performing notations, staging, dramaturgy, communication

\section{Referencia normalizada:}

Lorente, J. I. (2013) Puesta en escena, notaciones escénicas y comunicación. Historia y Comunicación Social. Vol. $18 \mathrm{~N}^{\circ}$ Especial Noviembre. Págs. 127-137.

Sumario: 1. Introducción. 2. Didascalias, notaciones y puesta en escena. 3. La forma escénica. 4. Preceptiva clásica, escena moderna y escrituras performativas. 5. Bibliografía.

\section{Introducción}

Los procesos de escenificación teatral, coreográfica o performativa, al igual que otras prácticas escénicas, como la música o la puesta en escena cinematográfica son guiados por una serie de textos efímeros y diversamente articulados, denominados didascalias, cuadernos de dirección, indicaciones de escena, partituras o guiones, cada uno de los cuales tiene su propias convenciones, funciones y estrategias textua- 
les. Estas notaciones escénicas presentan las huellas del trabajo creativo que media entre el texto y la puesta en escena, si bien no siempre la escenificación representa la culminación de un proceso de adaptación, ni tan siquiera el sometimiento de ésta a las indicaciones de su pretexto dramático. Las prácticas escénicas contemporáneas, al tiempo que impugnan la determinación dramatúrgica de la puesta en escena, requieren que ésta exprese su propia teoría, bajo la forma de un proyecto comunicativo que involucra y moviliza la figura del espectador. Este proyecto comunicativo hace del texto escénico, tanto se trate de un texto dramático en el que se vierten las indicaciones para la escena, como de un conjunto de anotaciones recogidas en una bitácora o cuaderno de dirección, un objeto interdisciplinar pertinente para el estudio de los procesos escénicos y creativos en general.

Sin embargo, en el enfoque teórico y metodológico de la investigación de las artes escénicas se observa una fuerte dependencia de los diseños y procedimientos de investigación vinculados a las disciplinas académicas consolidadas. Así, puede apreciarse un programa de investigación relevante en torno al texto dramático como objeto de análisis privilegiado (filología, estudios literarios, estética, historia), en detrimento del estudio de los procesos de escenificación y de la teatralidad, de especial relevancia en el pensamiento escénico contemporáneo. El propio dispositivo teatral, la crítica y los medios de comunicación han contribuido también a la consolidación y a la difusión de una concepción escénica disciplinada, fragmentada y escindida entre un pretexto dramatúrgico, al que se le reconoce el valor de texto literario, y una serie de actividades artísticas a través de las cuales toma cuerpo el espectáculo escénico, pero cuya apreciación se halla sometida a una pretendida adecuación al texto dramático de referencia. Esta supeditación de la escena al texto, al poner el énfasis en lo que el texto dice e indica, resta atención a la concepción y desarrollo de la propuesta escénica y a las estrategias discursivas destinadas a movilizar la figura y competencia del espectador. En este contexto, las prácticas escénicas contemporáneas han generado un giro de alcance epistémico que afecta no solo al modo de construir y desarrollar el proyecto escénico, sino también a la forma de pensar y de investigar los procesos de creación escénica. Este giro se ha concretado en una disolución de los tradicionales marcos disciplinares que disponían la dramaturgia y la escenificación como una secuencia de operaciones especializadas, produciendo un prolífico diálogo entre los discursos teóricos y las prácticas escénicas (Bellisco, 2011:25), desde las escrituras dramáticas hasta el espectáculo escénico. Ese mismo giro reclama también una aproximación analítica interdisciplinar (Bal, 2004:14), característica de los estudios visuales (Brea, 2005), capaz de dar cuenta tanto de la complejidad e hibridación de las prácticas y procesos de creación escénica, como de la forma de conceptualizar y de analizar los nuevos objetos escénicos en un campo de teatralidad expandida (Sánchez, 2006:28).

El campo interdisciplinar de los estudios visuales surge como consecuencia del desbordamiento operado por la fenomenología visual en los límites de lo artístico y lo estético, para advertir de su implicación en todos los ámbitos del saber. De esta forma, si bien la estética privilegiaba la determinación del objeto y del gesto sobre la 
mirada, el enfoque comunicativo ampliado por la cuestión de la visualidad se interesa por las condiciones de visibilidad (Foucault, 1991:133), por el modo en que en un determinado régimen visual éstas se ha institucionalizado y por el modo también en que los discursos visuales realizan, actualizan y reproducen esa institucionalización.

Los regímenes de visualidad representan un anudamiento inextricable entre el acto de observación y lo observado, entre las condiciones socio-históricas, culturales e ideológicas que median entre la percepción y el objeto de la mirada. Desde esta perspectiva, el análisis comunicativo del modo en que se construye la relación entre mirada y objeto, entre las estrategias comunicativas desplegadas por éste y la movilización de determinadas competencias en el espectador, abre nuevas vías de indagación crítica del espectáculo y la reconstrucción del compromiso ético e ideológico en el que se desenvuelven las prácticas escénicas.

\section{Didascalias, notaciones y puesta en escena}

La didascalia, del griego gr. $\delta 1 \delta \alpha \sigma \kappa \alpha \lambda i ́ \alpha$, enseñanza, consiste en un conjunto de indicaciones dadas por el autor a los actores con el fin de orientar la interpretación, sobre la escena, de un texto dramático.

El uso de las didascalias en los textos dramáticos indica cierta preocupación por parte del autor ante los procesos de puesta en escena, si bien esta preocupación no ha sido constante a lo largo de la historia del teatro. Así, mientras en el teatro griego el autor del texto era probablemente el responsable también de su puesta en escena, por lo que no requería de mayores precisiones acerca de su realización, el teatro latino incorpora una relación de dramatis personae, mediante la cual, además de identificar y caracterizar brevemente a los personajes del drama, se identifica también la perspectiva del autor sobre sus personajes, al tiempo que se orienta la recepción y el trabajo interpretativo del espectador. El nombre del personaje aporta información relevante acerca del origen o procedencia del mismo y nunca está exento de connotaciones morales, éticas o políticas. De esta forma, la didascalia orienta preventivamente cierta lectura ideológica y juicio sobre el drama.

La didascalia, como dispositivo comunicativo que identificaba papeles y funciones en el intercambio escénico, entre autor, espectador y personajes, no se desarrolló como una auténtica puesta en escena hasta que en el siglo XIX la figura del director de escena se convierte en el responsable de la organización del espectáculo. En ese momento se produce una transformación profunda del dispositivo comunicativo del espectáculo teatral debido, entre otras razones, al desbordamiento de la preceptiva clásica, a la crisis del drama, al desarrollo y especialización de las escenotecnias y de la máquina escénica y muy especialmente, debido a un profundo cambio en el público teatral que deja de ser un colectivo homogéneo y netamente diferenciado en función del tipo de espectáculos que se le ofrece. 
La fragmentación y diferenciación del público teatral, junto con la disolución de la preceptiva neoaristotélica provoca la disolución del acuerdo previo establecido entre el público y los creadores, en lo referente al género, a la estética y al sentido de la obra teatral. La escena comienza a tomar autonomía y distancia crítica respecto del texto dramático y comienza a establecerse un diálogo de pares entre el creador dramático y el creador escénico, en el seno de una dramaturgia expandida que a partir de ese momento incorpora nuevas teorías y prácticas de puesta en escena.

En el siglo XX la puesta en escena se considera la parte "específicamente teatral del espectáculo" (Artaud, 1964:61), "la proyección sobre el escenario de aquello que el dramaturgo solo ha podido proyectar en el tiempo" (Appia, 1954:38), dando así respuesta "al tipo de enunciación del texto dramático que contiene la exigencia de ser representado" (Ricoeur, 1995:89), mediante una puesta en forma escénica que es una interpretación de una escritura dramática, de un texto o de unas notaciones escénicas. El acto, la actuación por parte del actor, inscrita en una determinada configuración espacio-temporal, es lo que dota de autonomía a la escena respecto de sus pretextos, con los que establece una suerte de diálogo que reclama junto con la lectura del director de escena, la participación activa por parte del espectador. Consecuentemente, las notaciones escénicas dejan de ser una mera extensión de un texto y una convención genérica previa, para transformarse en un artefacto mediador entre el público y sus pretextos dramáticos, plásticos y visuales, una especie de dispositivo intertextual que guarda memoria del proyecto escénico y del proyecto de sentido que la escena performará ante el espectador.

Las didascalias y notaciones para la puesta en escena se confrontan así con la tradicional fragmentación disciplinar característica del dispositivo teatral, y con la presunción de una representación concebida para su estabilización y reproducción ad infinitum, lo que iba en detrimento de lo propio del acontecimiento teatral, de su singularidad y transformación en cada encuentro con el espectador. Esa misma tradición había privilegiado el producto frente al proceso, tergiversando con ello la idea misma de teatralidad. Pero en el pensamiento contemporáneo, el espectáculo escénico es concebido como un proceso en curso, en desarrollo, el cual a la vez que se actualiza en cada presentación, incorpora esa experiencia con capacidad para transformar potencialmente el proyecto escénico y su relación con el espectador.

Las prácticas escénicas contemporáneas han venido a refutar este marcado sesgo disciplinar, poniendo el énfasis en los procesos de escenificación y en el modo en el que la escena se configura como el espacio inestable y variable de un denso entrecruzamiento de concepciones dramatúrgicas, comunicativas y espectatoriales. Y dado que las notaciones escénicas guardan memoria del modo en que históricamente se ha pensado y practicado la escena (teatral, coreográfica, espectacular) constituyen también un objeto de indagación significativo para la investigación, tanto de las propias prácticas escénicas como del proyecto comunicativo que las anima.

A este respecto, cabe destacar que las notaciones escénicas reúnen una serie de características relevantes desde el punto de vista comunicativo. El proyecto de esce- 
nificación inscrito de forma explícita o implícita en el texto dramático presenta esa cualidad interdisciplinar e intersemiótica que pone a dialogar el texto literario con todo un repertorio de textos y prácticas artísticas, a través de las cuales se proyecta y eventualmente se realiza la puesta en escena, desde la construcción de una determinada configuración espacio-temporal, hasta la concepción del sujeto, del movimiento y de la acción que, literalmente, tomarán cuerpo en ella.

Las notaciones escénicas devienen así en operadores de transformaciones que ponen entre paréntesis la concepción unificada y unitaria de autoría para reclamar a la obra que ponga en escena no ya un determinad texto teatral, sino un diálogo a tres bandas entre texto, escena y espectador.

\section{La forma escenica}

El estudio de la forma en las prácticas escénicas orienta el foco de atención hacia la manera en que el proyecto escénico propicia un encuentro entre una ideología, un conjunto variable de ideas y valores acerca de la teatralidad, lo que constituye su forma del contenido, y una disposición estética de materiales expresivos articulados, mediante códigos, lenguajes y prácticas que constituyen su forma expresiva. Este particular encuentro entre una forma de pensar la escena y una forma de practicarla, presenta las huellas de un trabajo cuyo rastro ha quedado inscrito en las diferentes notaciones y escrituras escénicas, desde las didascalias clásicas, hasta las escrituras performativas contemporáneas. La investigación del proyecto comunicativo que ha movilizado ese trabajo pretende arrojar luz sobre una historiografía de la visualidad escénica, del pensamiento teatral y de su práctica, en el interior mismo de los procesos creativos. Este procedimiento de análisis aborda las notaciones escénicas como auto-etnografías del modo en que ha sido conducido el desarrollo del proyecto escénico.

El proyecto escénico moderno cuestionó y sometió a revisión crítica la dramaturgia clásica y el modelo comunicativo subyacente, orientado hacia la manipulación del espectador bajo los principios de la mímesis verosímil, la causalidad y la identificación. Para ello, los renovadores de la escena moderna emprendieron la construcción de la "escena total" wagneriana mediante procedimientos de montaje (Meyerhold), de integración de diferentes materiales expresivos (Appia, Craig, Dalcroze), o recurrieron a composiciones escénicas que, a modo de partituras, refutaban la centralidad del texto dramático (Stanislavski, Vajtangov, Schönberg, Kandinsky), incorporando los más diversos artefactos vanguardistas (Jarry, Piscator), épicos y antidramáticos (Artaud, Brecht).

Pero partir de los años 60 , no se trata ya tanto de incorporar al espectador a la escena, como pretendían los renovadores de la escena moderna, como de cuestionar el dispositivo espectacular en su globalidad, apelando a la cooperación del espectador "en acto", para su realización. Para ello, la escena enmudece, agota la dramaturgia 
que animaba el proyecto escénico y se hace el silencio, abriendo un profundo interrogante sobre la significación del lenguaje y de la palabra (Beckett), de la narratividad y del cuerpo (John Cage, Merce Cunningham, Living Theatre), y de la acción desprovista del drama, contaminada por otras prácticas artísticas, plásticas y coreográficas (Fluxus, Judson Dance Theater). La escena queda vacía (Ann Halprim, Peter Brook) para llamar la atención acerca de la inmediatez de la acción y del gesto en un espacio que ya no se configura como una escena separada, sino que se pretende estrechamente conectada con la vida. Frente a la autonomía del arte y de las fronteras entre las disciplinas artísticas, la escena contemporánea aspira a la experiencia de una "realidad total" (Tadeusz Kantor, Heiner Müller, Robert Wilson, Pina Bausch), inmersiva, sensible y susceptible de significados plurales que desbordan la expectativa de una lectura determinada por el pretexto dramático.

La escena se plantea entonces como un "campo situacional compartido", en el cual el espectador puede establecer un diálogo singular con la propuesta escénica, abierto a todo tipo de resonancias y contaminaciones intertextuales, atento al proceso mismo a través del cual se desenvuelve la relación comunicativa y donde el sentido de la experiencia se mantiene en estado de continua reconstrucción.

\section{Preceptiva clásica, escena moderna y escrituras performativas}

En la perspectiva de los estudios visuales, el interés no se centra en lo que la escena representa, sino en indagar cómo se ha construido esa escena a través de la historia, de las instituciones artísticas, de los dispositivos comunicativos y de los discursos mediáticos, para advertir las huellas que han dejado en él esa construcción e interrogarlas desde una perspectiva interdisciplinar que dé cuenta de las prácticas artísticas en tanto que prácticas sociales.

El teatro es el lugar de la mirada a través de la cual se diseña el encuentro con el Otro-espectador mediante una regulación estratégica de la distancia. La gestión de la distancia y de la alteridad, del espectador con el que el espacio escénico se propone dialogar, es una de las problemáticas específicas del campo artístico y de las prácticas escénicas contemporáneas.

Uno de los momentos de inflexión del pensamiento escénico y del lugar del espectador en el espectáculo teatral fueron las querelle entre antiguos y modernos, las cuales representaron, en las postrimerías del siglo XVII, una confrontación estético-ideológica entre los continuadores de la doxa aristotélica, exacerbada por las lecturas académicas de la Poética, y los dramaturgos que reivindicaban mayor libertad en el tratamiento del proyecto escénico.

La querelle constituye un momento de giro, de cambio en el paradigma artístico, "una figura epistemológica que [...] representa la disolución del clasicismo y la construcción de lo moderno" (Marchán, 2010:13). Esas disputas histórico-artísticas entre "antiguos" y "modernos" discurrían en el ámbito de una metafísica de lo bello, 
mediante la cual se confrontaba la confianza clásica en una belleza absoluta y positiva con una concepción moderna de la belleza más relativa y arbitraria, esto es, una estética basada en una incipiente semiótica desde la que se cuestiona la imposición del clasicismo como lenguaje único y universal, en favor de las diversas maneras de hacer, de las prácticas artísticas y escénicas. El ideario clásico de la época se basaba en el énfasis en las codificaciones y en la aspiración a una lengua universal acorde con el dictado de la Academia, creada a imagen del poder de la monarquía absolutista, y de una concepción normativa basada en una interpretación ideológica y radical de las grandes obras de la antigüedad griega y romana (Foucault, 1991).

La dramaturgia de Meininger puso las bases del director de escena y de la disciplina aplicada a los detalles del escenario y al movimiento de los actores en la escena, lo que constituyó una primera regiduría y con ella la inscripción de un punto de vista interno, estético y funcional de la escena. El realismo histórico aplicado a la construcción escénica moderna, junto con la atención al movimiento de los actores en ese espacio, construido y significante a la vez, requería un prolijo abanico de instrucciones e ilustraciones debido a que el diseño escénico, realizado mediante dibujos, diagramas o pinturas, adquirió tanta importancia como el propio texto dramático en la formación de una única mirada de dirección. Ya en el umbral del siglo XIX el método psicológico-realista de Stanislavski plantea la puesta en escena actoral como un ahondamiento en el proceso creativo en el que se ha inspirado el texto dramático. La escena dialoga con el texto, pero no lo hace a través de sus indicaciones explícitas, como una mera ilustración del argumento, sino como una investigación de su sentido profundo.

El rechazo de las prácticas realistas adquiere, con Alfred Jarry (Ubú rey, 1896), la forma de una mirada irónica sobre el teatro trágico y sus personajes, ambientes y convenciones, para dar paso a las vanguardias del siglo XX, a la propuesta de destrucción de la escena, anunciada por teatro dadaísta, y su reconstrucción en clave simbolista y antinaturalista, partiendo de nuevos presupuestos musicales, luminotécnicos y objetuales (Adolphe Appia) o puramente rítmicos (Gordon Craig). Estas formas escénicas alcanzan también al trabajo actoral que será esquematizado, reducido a mero componente plástico, la marioneta, carente de psicología y de motivación, pero dotada de una carga simbólica capaz de indagar en las capas profundas del sentido. La dirección de escena deja de ser una función auxiliar del dramaturgo, para tomar el control de todo lo que tiene que ver con la escenificación.

Con Beckett esos postulados teóricos apenas realizados por los precursores de la escena moderna, toman cuerpo en obras como Esperando a Godot (1952) y especialmente, en Final de partida (1957). El título alude al juego del ajedrez, en el que el espacio geométrico del tablero solo permite ciertos movimientos codificados de las piezas. Las minuciosas didascalias de la obra anticipan y determinan todos y cada uno de los elementos del juego escénico, pero esta codificación de la escena no se presenta como un subtexto del texto dramático, ni como un pretexto de la puesta en escena, sino que constituye una forma más de concreción del drama, acaso la más relevante. La obra se levanta sobre el entramado simbólico del juego a punto de 
finalizar, mediante un intrincado diálogo entre la forma del contenido, un mundo deshumanizado, reducido a su mínima y desoladora caracterización y una forma de la expresión de la que se ha evacuado, así mismo, todo atisbo humano y emocional.

El deseo de ver del espectador queda en suspenso por este despojamiento de la escena postdramática y antinaturalista para dirigir la atención hacia el sustento ideológico del drama. Gracias a estas torsiones de la forma teatral, el deseo de ver del espectador que la escena moderna trataba de satisfacer mediante la saturación de indicios realistas verosímiles, es ahora frustrado bajo la premisa de un nada para ver que reclama con insistencia el trabajo interpretativo del espectador. Las notaciones escénicas participan de este recorrido mediante una progresiva transformación en partituras y bitácoras de dirección, a través de cuales se trata más de coreografiar y documentar el proceso de escenificación, que de ilustrar los contenidos descriptivos del texto dramático.

Las partituras coreográficas de Ivanov, las labanotaciones de Rudolf Laban, las semiografias de Jacques Polieri, los visual scripts, de Cole o los labbyrinthos, de Anestis Logothetis, jalonan este recorrido conceptual que acompaña el desmontaje de una idea de la escena como mera realización de una lectura canónica, recta y apropiada de su pretexto dramático.

Otros desmontajes, basados en la distanciación y el extrañamiento antidramático del espectador respecto de la escena, son documentados por los modelbook brechtianos, cuadernos de investigación escénica a través de los cuales el dramaturgo indagaba y movilizaba una mirada crítica sobre el gestus social del que el propio espectador participaba. Este punto de vista documentado prestaba especial atención al proceso, a las opciones tomadas a lo largo del desarrollo del proyecto escénico. El modelbook es un registro verbo-icónico del proceso creativo que incorpora, junto las indicaciones de puesta en escena, conceptos y teorías escénicas. No se trata tanto de una memoria del proceso creativo, como del registro de un proyecto intelectual cuya realización queda abierta a múltiples experiencias y reconstrucciones escénicas. Frente a la pretendida cohesión y articulación dramatúrgica, diversos autores, como Walter Benjamin o George Didi-Huberman, observan que el teatro épico de Brecht avanza por sacudidas, mediante choques, a través de los cuales situaciones particulares de la obra, muy distintas las unas de las otras, colisionan creando intervalos que obstaculizan la ilusión del público, para desembocar en una "toma de posición crítica" que "amplía el laboratorio teatral para recomponer las fuerzas de lo político por descomposición y exposición analítica de la historia» (2008:150). La forma épica actúa en el interior del dispositivo teatral como un procedimiento heurístico y un modo de observación histórica. A diferencia de la dramaturgia clásica, guiada por la lógica causal y la necesidad, de tal forma que el sentido queda orientado y colapsado por la catarsis hacia la que apunta todo el desarrollo argumental, la forma épica indaga en la red de relaciones que se esconde tras los acontecimientos, esa otra realidad oculta tras la representación que pide al observador multiplicar sus puntos de vista. El teatro épico no reproduce estados del mundo sino que propone puntos de 
vista alternativos para su descubrimiento, mediante la interrupción de su desarrollo dramático.

Finalmente, en este recorrido se presenta una última deconstrucción de carácter performativo, aquella que anticipaba Jerzy Grotowski al afirmar que "la notación no es posterior al acto sino que que coincide con él", y que continuará Antonin Artaud, en El teatro y su doble (1938), bajo la fórmula "hacer teatro y a la vez decir ese teatro". Artaud busca sobrepasar la escena como refracción de un texto literario previo. Si para Grotowski el actor escribe, produciendo con su cuerpo jeroglíficos que son a la vez el signo y la cosa, los jeroglíficos artaudianos pretenden componer una escena legible directamente, escribiéndola directamente sobre el espacio escénico mediante un lenguaje cifrado de signos ideográficos que a la vez que representan el objeto, incorporan ideas o cualidades asociadas a él. En los Cuadernos de Rodez (1946), Artaud afirma que sus dibujos no son representaciones, no figuran, sino que se trata más bien de glosolalias, una forma de escritura para el cuerpo, una escritura performativa que toma cuerpo en la escena. Para el autor, la partitura ya no es un instrumento de notación, ni un metalenguaje, sino un objeto en proceso y una práctica artística en curso, una escritura, en definitiva, compuesta por gestos, actitudes y signos que se inventan a medida que son pensados y realizados directamente sobre la escena. Ya no hay una escritura previa y una escena posterior, sino que ambas constituyen un mismo acto a través de una escritura que performa su propia puesta en escena.

Esta escritura escénica performa también la participación del espectador bajo la forma de una escena compartida, como una comunidad de participantes que no se funda ya en la convención y en el reconocimiento y apropiación de un significado dado, prefigurado por el texto, sino en el disenso y en la manifestación de ese otro-espectador con el que la interacción se desarrolla de forma imprevisible. La experiencia previa del espectador, su competencia intertextual, el archivo y la memoria, junto con su propio cuerpo, son convocados por esta escena que se muestra esquiva y renuente a la imposición de un sentido previamente fabricado, apropiado, recto (Pardo, 2011:32).

Las escrituras performativas adquieren entonces la forma de una mirada implicada, reflexiva y participante, que al tiempo que impugna la relación espectacular clásica y desborda la distancia sobre la que ésta se instauraba, proyecta sobre la escena contemporánea el proyecto de un diálogo, una conversación en torno a la cual la competencia del espectador es movilizada y confrontada, para tomar parte en una escena que se ha vuelto irrepresentable.

\section{Conclusiones}

La escena contemporánea ha desplazado el foco de atención de la representación a la relación espectatorial, con el doble propósito de hacer de ella su objeto de inda- 
gación privilegiado y una estrategia de confrontación con los presupuestos heredados de la tradición.

La performance destruye la ilusión de la representación, transformándola en presentación, en juego con un espectador que, al tiempo que actúa, desbarata cualquier posibilidad de repetición. Esta escena irrepetible e irrepresentable pone en cuestión la idea de una notación escénica que pretenda anticipar y pautar su desarrollo y debido a su imprevisibilidad, confronta también cualquier anticipación y expectativa de recepción por parte del espectador.

El proyecto que anima la escena es crítico, pretende la transformación de las condiciones sociales, culturales y políticas de producción de la teatralidad y en su dimensión ética, busca la creación de comunidades de discurso a través de una experiencia escénica compartida que no está exenta de implicaciones éticas y políticas.

Finalmente, este giro introducido por las prácticas escénicas contemporáneas tiene consecuencias tanto para la experiencia artística y escénica, como para la investigación, la producción del conocimiento y la pedagogía de las artes escénicas y performativas.

\section{Bibliografía}

APPIA, A. (1954) «Acteur, espace, lumière, peinture», En: Théâtre populaire, ${ }^{\circ} 5$ Enero-Febrero. París. p.37-42

ARTAUD, A. (1964) El teatro y su doble. Buenos Aires: Ed. Sudamericana

BAL, M. (2004). «El esencialismo visual y el objeto de los estudios visuales: Ensayo, teoría y crítica de la cultura visual y el arte contemporáneo». En: Estudios Visuales, $\mathrm{n}^{\circ} 2, \mathrm{p} .11-49$

BELLISCO, M. (Ed.) (2011). Repensar la dramaturgia. Errancia y transformación. Murcia: Cendeac

BENJAMIN, W. (1939) «¿Qu'est-ce que le tehéâtre épique?», En: Essais sur Brecht. Paris, La Fabrique

BREA, J.L. (2005) Estudios visuales. La epistemología de la visualidad en la era de la globalización. Madrid: Akal. Estudios Visuales

DIDI-HUBERMAN, G. (2008) Cuando las imágenes toman posición. Madrid: Antonio Machado Libros

FOUCAULT, M. (1991) Las palabras y las cosas. México: Siglo XXI

MARCHAN, S. (2010). La disolución del clasicismo y la construcción de lo moderno. Salamanca: Ediciones Universidad de Salamanca

PARDO, J.L. (2011). Estética de lo peor. Barcelona: Ediciones Barataria

RICOEUR, P. (1995) Tiempo y narración. México: Siglo XXI

SÁNCHEZ, J.A. (2002) Dramaturgias de la imagen. Cuenca: Universidad de Castilla-La Mancha 


\section{El autor}

José Ignacio Lorente. Profesor Titular de Universidad en el Departamento de Comunicación Audiovisual, de la Universidad del País Vasco/Euskal Herriko Unibertsitatea. Director del Máster Universitario en Artes y Ciencias del Espectáculo. Coordinador del proyecto de investigación "Dramaturgia, escenificación y transmedialidad. Análisis crítico del concepto de puesta en escena desde la perspectiva de los estudios visuales". 